\title{
Thin layer modelling of hybrid, solar and open sun drying of tomato slices
}

\author{
J. B. Hussein ${ }^{1}$, K. B. Filli' ${ }^{1}$ and M. O. Oke ${ }^{2^{\star}}$ \\ 1Department of Food Science and Technology, Modibbo Adama University of Technology Yola, P. M. B. 2076, Yola, \\ Adamawa State, Nigeria. \\ ${ }^{2}$ Department of Food Science and Engineering, Ladoke Akintola University of Technology Ogbomoso, P. M. B. 4000, \\ Ogbomoso, Oyo State, Nigeria. \\ *Corresponding author. Email: ola4ade@yahoo.com, mooke47@lautech.edu.ng
}

Copyright $@ 2016$ Hussein et al. This article remains permanently open access under the terms of the Creative Commons Attribution License 4.0, which permits unrestricted use, distribution, and reproduction in any medium, provided the original work is properly cited.

Received 29th February, 2016; Accepted 24th May, 2016

\begin{abstract}
The thin layer drying behaviour of tomato slices dried using hybrid drying method as well as solar and open sun drying was investigated. Six thin layer drying models (Page, Logarithmic, Henderson and Pabis, Newton (Lewis), Wang and Singh and Parabolic) were used to optimize the goodness of fit to the experimental data. The models were compared using coefficient of determination $\left(R^{2}\right)$, chi-square $\left(\chi^{2}\right)$ and root mean square error (RMSE). The tomato slice dried faster when subjected to hybrid drying method compared to other methods. Tomato slices of 4,6 and $8 \mathrm{~mm}$ thicknesses were dried from 94.22 to $10 \%$ (wet basis), for 300, 360, 420 minutes respectively in hybrid drying method. However, it took 420, 510, 600 and 510,630, $840 \mathrm{~min}$ in solar and open sun drying respectively. The drying took place only in a falling rate drying period. The Page model was found to fit the experimental data better as compared to other models. The effective moisture diffusivity values were found to be between $2.00 \times 10^{-10}$ and $5.84 \times 10^{-10} \mathrm{~m}^{2} / \mathrm{s}$ in hybrid dried slices, $1.37 \times 10^{-10}$ and $4.40 \times 10^{-10} \mathrm{~m}^{2} / \mathrm{s}$ in solar dried slices and $1.33 \times 10^{-10}$ and $4.01 \times 10^{-10} \mathrm{~m}^{2} / \mathrm{s}$ in open sun dried tomato slices of 4 to $8 \mathrm{~mm}$ thicknesses. The results of these measures have confirmed the consistency of the developed model to describe satisfactorily the thin-layer hybrid, solar and open sun drying characteristics of tomato slices.
\end{abstract}

Keywords: Drying equation, hybrid dryer, moisture content, solar dryer, tomato slice.

\section{INTRODUCTION}

Tomatoes (Lycopersicon esculentum L.var) are one of the most important grown vegetable crops, mostly in the tropical countries. It is highly seasonal and available in large quantities at a particular season of the year. Due to market glut during peak season large quantity of tomato gets spoiled. Processing, preservation and storage of tomatoes during peak season can prevent the huge postharvest losses in tomato and make them available in the off season at comparatively lesser cost. Tomatoes and tomato products are rich in health valued food components such as carotenoids (Lycopene), ascorbic acid (Vitamin C), vitamin E, folate and dietary fibre
(Davies and Hobson, 1981; Rajkumar, 2007). Dehydration processes offer an alternative way of using tomato for consumption and the dehydration of tomato has been practiced for many years as a means of preservation.

Tomatoes, as other vegetables, can be dried using various methods. In any tomato drying technique the required time for drying the product depends on many parameters such as tomato variety, the soluble solids content ( ${ }^{\circ}$ brix) of the fresh product, the air humidity, the size of the tomato segments, the air temperature and velocity and the efficiency of the drying system. The rate of drying affects the end quality of the dried product 
(Andritsos et al., 2003). In general, dried tomatoes undergo the following process steps: pre-drying treatments, (such as size selection, washing and tray placing), drying or dehydration, and post-dehydration treatments, such as inspection, screening and packaging (Andritsos et al., 2003).

Sun drying of agricultural products is the traditional method employed in most of the developing countries. Sun drying is used to denote the exposure of a commodity to direct solar radiation and the convective power of the natural wind. Sun drying offers a cheap method of drying but often results to inferior quality of products due to its dependence of weather conditions (Amer et al., 2010). Andritsos et al. (2003) reported that traditional sun-drying of tomatoes has the advantages of simplicity and the small capital investments, but it requires long drying times that may have adverse consequences to the product quality: the final product may be contaminated from dust and insects or suffer from enzyme and microbial activity. On the other hand, solar energy drying is an alternative which offers several advantages over the traditional method and it has been developed for various agricultural products. Solar energy for crop drying is environmentally friendly and economically viable in the developing countries. It's also form a sustainable energy that has a great potential for wide variety of applications because it is abundant and accessible, especially for countries located in the tropical region. Solar-energy drying overcomes the drawbacks of traditional open sun drying such as, contamination from dust, insects, birds and animals, lack of control over drying conditions, possibility of chemical, enzymatic, and microbial spoilage due to long drying times (Ajay et al., 2009; Gutti et al., 2012). Solar drying offers an alternative which can process the vegetables and fruits in clean, hygienic and sanitary conditions, to acceptable national and international standards. It saves energy, time, occupies less area, improves product quality, makes the process more efficient and protects the environment (Funebo and Ohlsson, 1998; Zhang et al., 2006; Aware and Thorat, 2012).

However, one significant disadvantage of solar dryer is that it can only be used during the daytime when there is adequate solar radiation. That is they are normally constructed with no any form of back-up heating systems (Geramitcioski and Mitrevski, 2011). For commercial producers, this factor limits their ability to process a crop when the weather is poor. It can also extend the drying time because drying can only occur during the day time when there is solar radiation. This not only limits production but can result in an inferior product (Werner and Josef, 2003). For commercial producers, the ability to process continuously with reliability is important to satisfy their markets. Therefore, it is necessary to provide solarenergy dryer with additional source of energy such is the case of hybrid dryer (solar dryer with energy storage system).

In a hybrid solar dryer, drying is continued during off sunshine hours by back-up heat energy or storage heat energy. Therefore, drying is continued and the product is saved from possible deterioration by microbial infestation. Puiggali and Varichon (1982) reported that thermal storage during the day can be used as a heat source during the night for continuing drying of agricultural products and also preventing their re-hydration from the surrounding air. Continuous drying also prevents microbial growth during drying (Hossain and Gottschaslk, 2006). Also, it was found that storage and auxiliary heat supply can be used to assess compatibility of solar energy to meet the drying process temperature (Vlachos et al., 2002). Some hybrid dryers were developed to control the drying air conditions throughout the drying time independent of sun-shine especially at night or poor weather when it is not possible to use the solar energy, using alternative heating sources such as sawdust burner (Bassey, 1985); kerosene stove (Babarinsa 2006) or by using a biomass stove (Prasad and Vijay, 2005; Amer et al., 2010); electric heater (Boughali et al., 2009; Reyes et al., 2014). It is reported that significant improvement was registered after the heater is added to the solar dryer during periods of low sun-shine (Bennamoun and Belhamri, 2003).

In order to successfully transfer knowledge acquired experimentally from studies on food dehydration into industrial applications, mathematical modelling of drying kinetics is required. Moreover, a mathematical model is an important tool used to optimize operating parameters and to predict performance of a drying system (Babalis and Belessiotis, 2004). Numerous mathematical models, empirical and semi-empirical, have been proposed to estimate the drying characteristics of agricultural products (Mirzaee et al., 2010). These simple models, also known as thin layer models, allow prediction of mass transfer during dehydration and are applied to simulate drying curves under similar conditions (Doymaz, 2007; Purkayastha et al., 2013).

Many researches have been conducted on the mathematical modeling and experimental studies on thin layer solar drying processes of various vegetables and fruits, such as green bean (Doymaz, 2005), pistachio (Midilli and Kucuk, 2003), red pepper (Akpinar et al., 2003), mint leaves (Akpinar, 2010), tarragon (Arabhosseini et al. 2008), potato (Aghbashlo et al. 2009), chilli pepper (Tunde-Akintunde, 2011), carrot (Berruti et al., 2009), citrus aurantium leaves (Mohamed et al., 2005) and tomato slice (Kulanthaisami et al., 2010; Bagheri et al., 2013). However, few reports have focused on the drying kinetics of hybrid dried tomato slices. Therefore, the aim of this study was to evaluate the drying kinetics of hybrid and solar drying of tomatoes slices in relation to open sun drying using thin layer drying models. 


\section{MATERIALS AND METHODS}

\section{Raw Material Preparation}

The tomatoes used for this study were obtained from the Jimeta Modern Market, Yola, Adamawa State, Nigeria. Samples of tomatoes were selected from the lot based on firmness, colour and size uniformity. They were washed thoroughly with tap water, rinsed with distilled water and then wiped with an absorbent paper (Owusu et al., 2012). The hybrid dryer used in this study was a hybridphotovoltaic dryer which used photovoltaic (PV) solar panel to power the heating element coil and charging the battery which store energy. The heating sources of the dryer was used separately as solar dryer and combined as hybrid dryer. The dryer was used to dried slice tomatoes and compared with open sun drying under the weather condition of Adamawa State, Yola which was geographically located at the North Eastern part of Nigeria and lies between latitude 7 and $11^{\circ} \mathrm{N}$ and between Longitude 11 and $14^{\circ} \mathrm{E}$.

\section{Drying Procedures}

Drying experiments were carried out using a laboratory hybrid-photovoltaic solar dryer. Briefly, a schematic diagram of the experimental system is shown in Figure 1. The dryer consists of a DC extractor fan, drying chamber $\left(500 \times 500 \times 1100 \mathrm{~mm}^{3}\right)$, drying trays, collector (which is an absorber plate made of aluminum sheet painted black and a transparent glass of $5 \mathrm{~mm}$ thickness which permit in only sun radiation), air channel (air vent which is provided on the lower front side of the collector for easy passage of air into the dryer), DC blower fan and $500 \mathrm{~W}$ power heater located at the bottom of the drying chamber, two solar panel rated $180 \mathrm{~W}$ power each, solar battery rated $200 \mathrm{Ah}$ and a temperature sensor which was located at the center of the chamber to sense the chamber temperature.

The initial moisture content of the tomato samples was determined in an oven at a temperature of $105^{\circ} \mathrm{C}$ for $24 \mathrm{~h}$ (AOAC, 2004). The initial moisture content was $94.22 \%$ (wet basis) for tomatoes. The cleaned tomatoes were pretreated in boiling water for $2 \mathrm{~min}$, and drained. The samples were then divided into three portions. Then, each portion was sliced using slicer to a thickness of 4,6 and $8 \mathrm{~mm}$. The first portion of the slices $(4 \mathrm{~kg}$ and $4 \mathrm{~mm}$ thick) were spread in a single layer on a four different wire meshes (1 kg on each wire mesh) and sun dried until equilibrium moisture content was achieved. The second portion (4 $\mathrm{kg}$ and $4 \mathrm{~mm}$ thick) was dried in the constructed hybrid dryer by using solar collector as the heating source alone and the third portion $(4 \mathrm{~kg}$ and 4 $\mathrm{mm}$ thick) was dried by using both heating source together. One $(1 \mathrm{~kg})$ on each wire mesh tray and it was left until constant weight was achieved. This procedure was repeated for 6 and $8 \mathrm{~mm}$ respectively. Before each experiment, the dryer was started for one hour to achieve desirable steady state condition and during each run inlet air, ambient air temperature, sample weight and sample temperature were recorded as initial readings. The moisture content of the tomato slices of all the portions were monitored and measured at every 30 minutes until equilibrium moisture content was obtained. The drying process was finished when the sample reached the moisture content of $10 \%$. Then, the average weight of each try weight was taken and recorded.

\section{Mathematical Modelling}

\section{Determination of moisture ratio (MR)}

The moisture ratio of tomato slices dried under open sun drying, solar drying and hybrid drying at a given time, $t$ was calculated using a relationship;

Moisture Ratio $(M R)=\frac{M_{t}-M_{e}}{M_{i}-M_{e}}=e^{-k t} \quad$ Eq.1

Where: $M_{i}$ and $M_{e}$ are the initial and equilibrium dry basis moisture contents, \%, $\mathrm{M}_{\mathrm{t}}$ is dry basis moisture content at any time ' $\mathrm{t}$ ', $k$ is the drying rate constant per minute and $t$ is the drying time, min.

The values of $M_{e}$ are relatively small compared to $M_{t}$ and $M_{i}$, where error implied in the simplification is negligible. Drying curves were obtained for the tomatoes. The experimental moisture ratio versus drying time data were fitted in six thin layer drying models (Page, Logarithmic, Henderson and Pabis, Newton (Lewis), Wang and Singh, and Parabolic) widely used to describe the drying characteristics of most food products (Table 1). The best model was selected to describe the hybrid, solar and open sun drying processes of tomato slices (Akpinar, 2006 and Rajkumar, 2007). These models are generally derived by simplifying the general series solution of Fick's second law. The coefficient of determination $\left(R^{2}\right)$ was used as primary criteria for selecting the model that best fit the experimental data. In addition to the coefficient of determination, the best fit of the experimental data was also selected based on various statistical parameters such as the reduced chi-square $\left(x^{2}\right)$ as the mean square of the deviations between the experimental and predicted values for the models and root mean square error analysis (RMSE). To get the best fit of the experimental data, the coefficient of determination should be higher and the $x^{2}$ and RMSE should be lower (Akpinar et al., 2006; Tunde-Akintunde and Oke, 2012).

The statistical parameters were calculated by using the following relationships;

$\chi^{2}=\frac{\left[\sum_{i=1}^{N}\left(M R_{\text {pre }, i}-M R_{\text {exp }, i}\right)^{2}\right]}{N-n}$

Eq. 2 
Res. J. Food Sci. Nutr. 18

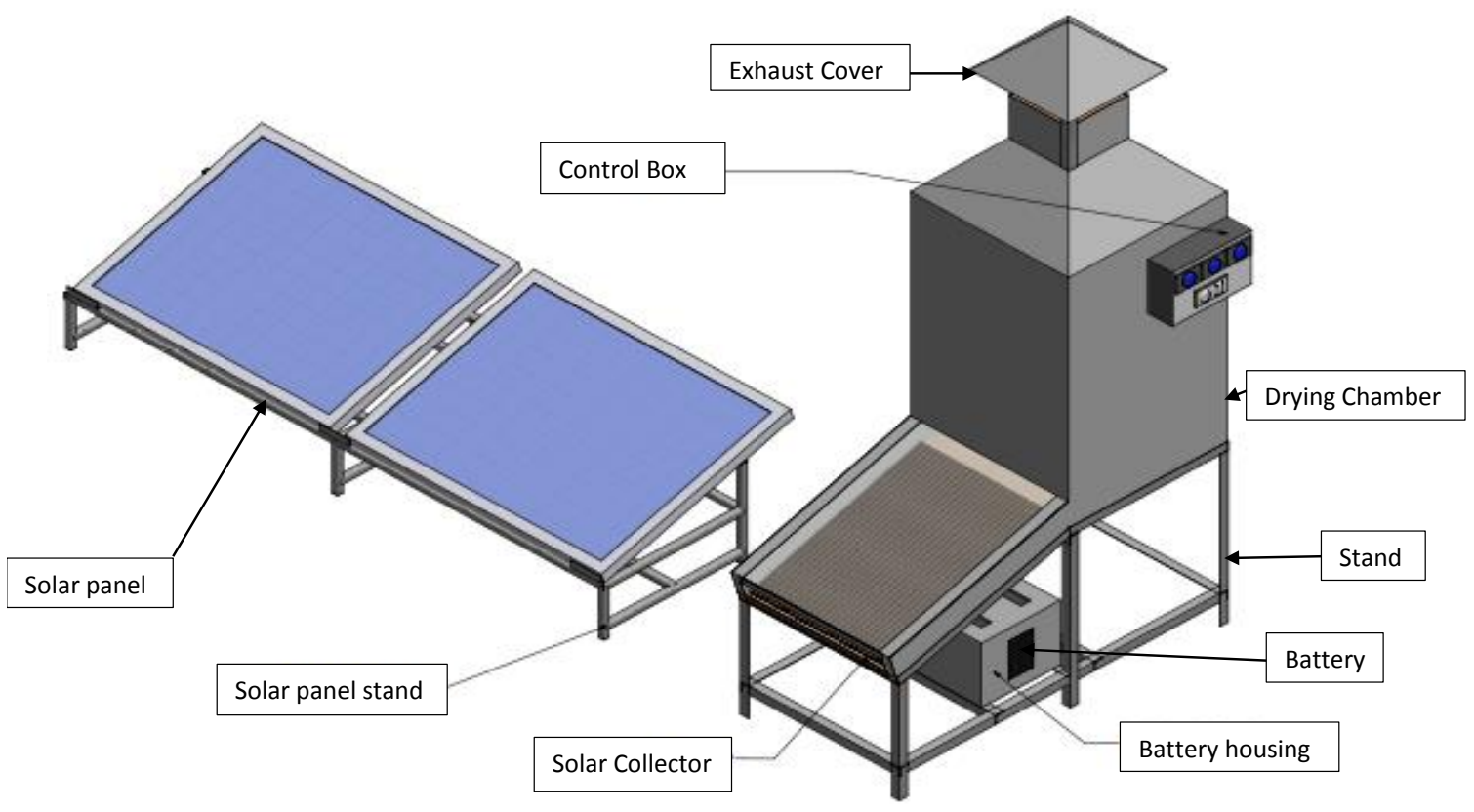

Figure 1: Isometric view of the Hybrid Dryer.

Table 1: Mathematical Models Fitted to Tomato Slice Drying Curves.

\begin{tabular}{|c|c|c|}
\hline Model Name & Model Equation & References \\
\hline Page & $M R=\exp \left(-k t^{n}\right)$ & $\begin{array}{l}\text { Doymaz, (2004); Da Silva et al., (2005); Singh et al., } \\
\text { (2006); Alibas, (2007); Jangam et al., (2008); Hassan- } \\
\text { Beygi et al., (2009). }\end{array}$ \\
\hline Logarithmic & $M R=a \exp (-k t)+b$ & $\begin{array}{l}\text { Doymaz, (2004); Kingsly et al., (2007); Xanthopoulos et al., } \\
\text { (2007); Khazaei et al., (2008); Tunde-Akintunde and Oke, } \\
\text { (2012) }\end{array}$ \\
\hline Henderson and Pabis & $M R=a \exp (-k t)$ & $\begin{array}{l}\text { Shittu and Raji (2011); } \\
\text { Tunde-Akintunde and Oke, (2012) }\end{array}$ \\
\hline Newton (Lewis) & $M R=\exp (-k t)$ & $\begin{array}{l}\text { Togrul and Pehlivan, (2002); Tunde-Akintunde, (2011); } \\
\text { Tunde-Akintunde and Oke, (2012) }\end{array}$ \\
\hline Wang and Singh & $\mathrm{MR}=1+\mathrm{kt}+\mathrm{ct} \mathrm{t}^{2}$ & Wang and Singh, (1978); Çelen et al., (2013) \\
\hline Parabolic & $M R=a+k t+c t^{2}$ & $\begin{array}{l}\text { Sharma and Prasad, (2004); Doymaz, (2010); Tunde- } \\
\text { Akintunde and Oke, (2012) }\end{array}$ \\
\hline
\end{tabular}

$\left.R S M E=\sqrt{\left[\frac{1}{N}\right.} \sum_{i=1}^{N}\left(M R_{\text {pre }, i}-M R_{\text {pre }, i}\right)^{2}\right] \quad$ Eq. 3

Where: $X^{2}=$ chi-square, $N=$ numbers of runs, $M_{\text {pre }}=$ predicted moisture ratio, $\mathrm{MR}_{\exp }=$ expected moisture ratio and $n=$ positive integer.

\section{Determination of moisture effective diffusivities}

Fick's equation is widely used for explaining drying mechanism of solid food material involving diffusion of vapour (Sankat and Castaigne, 2004). When a material dries mainly in the falling rate period, then it could be assumed that the internal moisture diffusion occurs. Therefore, moisture diffusivity in tomato slices can be calculated from the experimental drying data using Fick's second law for a slab shaped material. The solution to this equation developed by Crank (1975) can be applied for tomato slices of different thicknesses by assuming uniform initial moisture distribution as: 


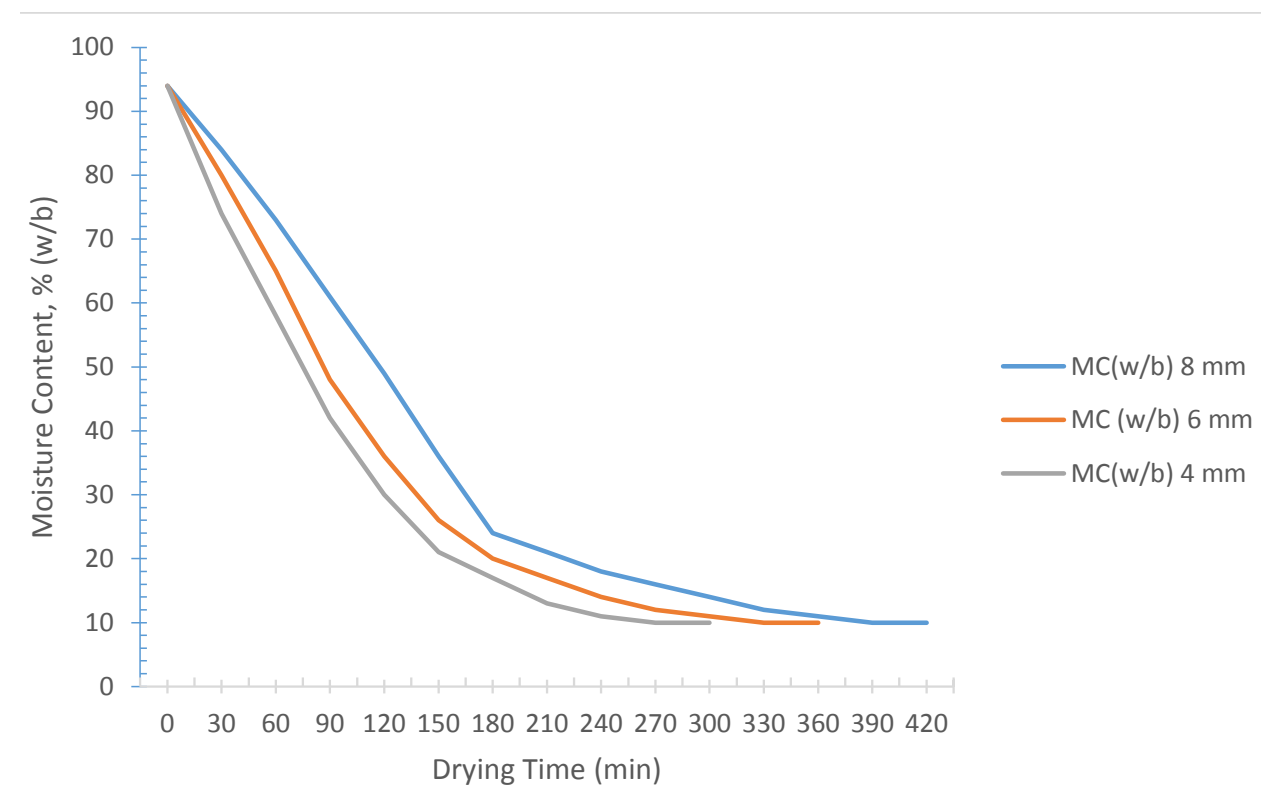

Figure 2: Drying Curve for Hybrid Drying Method.

$M R=\frac{8}{\pi^{2}} \sum_{n=0}^{\infty} \frac{1}{(2 n+1)^{2}} \exp \left(-\frac{(2 n+1)^{2} D_{e f f} \pi^{2}}{4 l^{2}} t\right) \quad$ Eq. 4

Where;

Deff is the effective moisture diffusivity, $\mathrm{m}^{2} / \mathrm{s}$;

$t$ is the drying time, $s$;

$L$ is the half thickness of a thin layer sample, $m$; and

$\mathrm{n}$ is a positive integer.

For long drying time, only the first term of equation 4 is significant (Tutuncu and Labuza, 1996) and then the solution becomes;

$M R=\frac{8}{\pi^{2}} \exp \left(-\frac{D_{e f f} \pi^{2}}{4 l^{2}} t\right) \quad$ Eq. 5

This could be further simplified to a straight-line equation as;

$\ln (M R)=\ln \left(\frac{8}{\pi^{2}}\right)-\left(\frac{D_{e f f} \pi^{2}}{4 l^{2}} t\right)$

The effective moisture diffusivity values were determined by plotting experimental drying data in terms of In (MR) versus drying time t. A plot of In (MR) versus drying time gives a straight line with a slope;
slope $=-\frac{D_{e f f} \pi^{2}}{4 l^{2}}$
Eq. 6

Knowing the tomato slice thickness and the slope from the above plot, the moisture diffusivity (Deff) was calculated.

\section{RESULTS AND DISCUSSION}

\section{Drying curves}

The change in moisture content of tomatoes slices with drying time in hybrid dryer, solar dryer and open sun drying was presented in Figures 2, 3 and 4 . It was observed that the total drying time for 4,6 and $8 \mathrm{~mm}$ thickness slices was $300,360,420$ min, respectively in hybrid drying, 420, 510, $600 \mathrm{~min}$, respectively in solar drying and 510, 630 and $840 \mathrm{~min}$, respectively in open sun drying. This shows that for a given thickness, the hybrid drying method required shorter drying time when compared to solar and open sun drying. Also solar drying required shorter drying time when compared to open sun drying method. In other words, drying time was reduced to about $28.57-30 \%$ of the total drying time spent for 4 $8 \mathrm{~mm}$ thickness tomato slices in hybrid dryer when compared to solar dryer, $41.18-50 \%$ in hybrid dryer when compared with open sun drying and 17.64 $28.57 \%$ in solar dryer when compared with open sun drying. The reduction in the total drying time of the hybrid dryer compared to solar dryer and open sun drying was observed to be due to higher temperature in the drying chamber of the hybrid dryer.

This result is in agreement with Rajkumar (2007) findings in which the drying time reduced significantly as the thickness of slices decreases, because the resistance to moisture movement is relatively higher in thicker slices than in thinner ones. This resistance was observed to decrease the drying rate, which resulted in increased drying time of $8 \mathrm{~mm}$ thick slices. Generally, it was observed 
Res. J. Food Sci. Nutr. 20

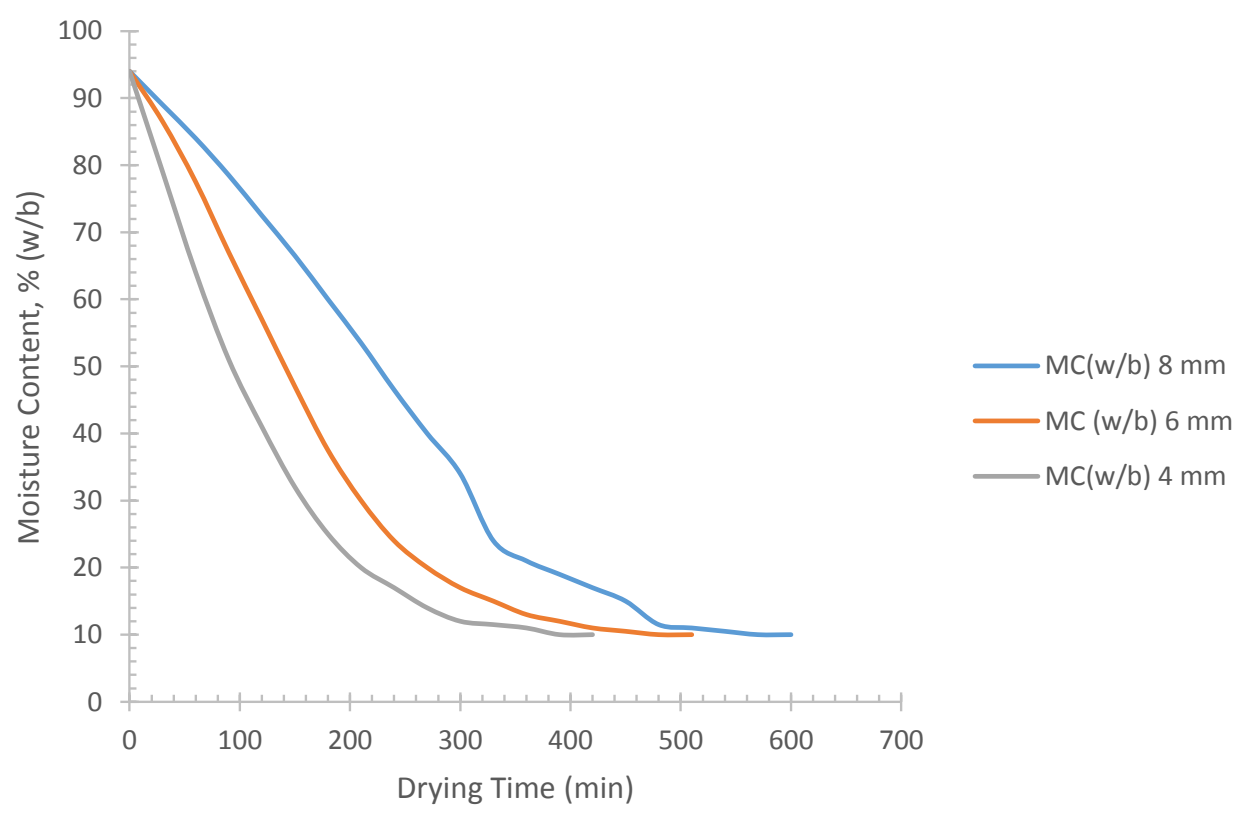

Figure 3: Drying Curve for Solar Drying Method.

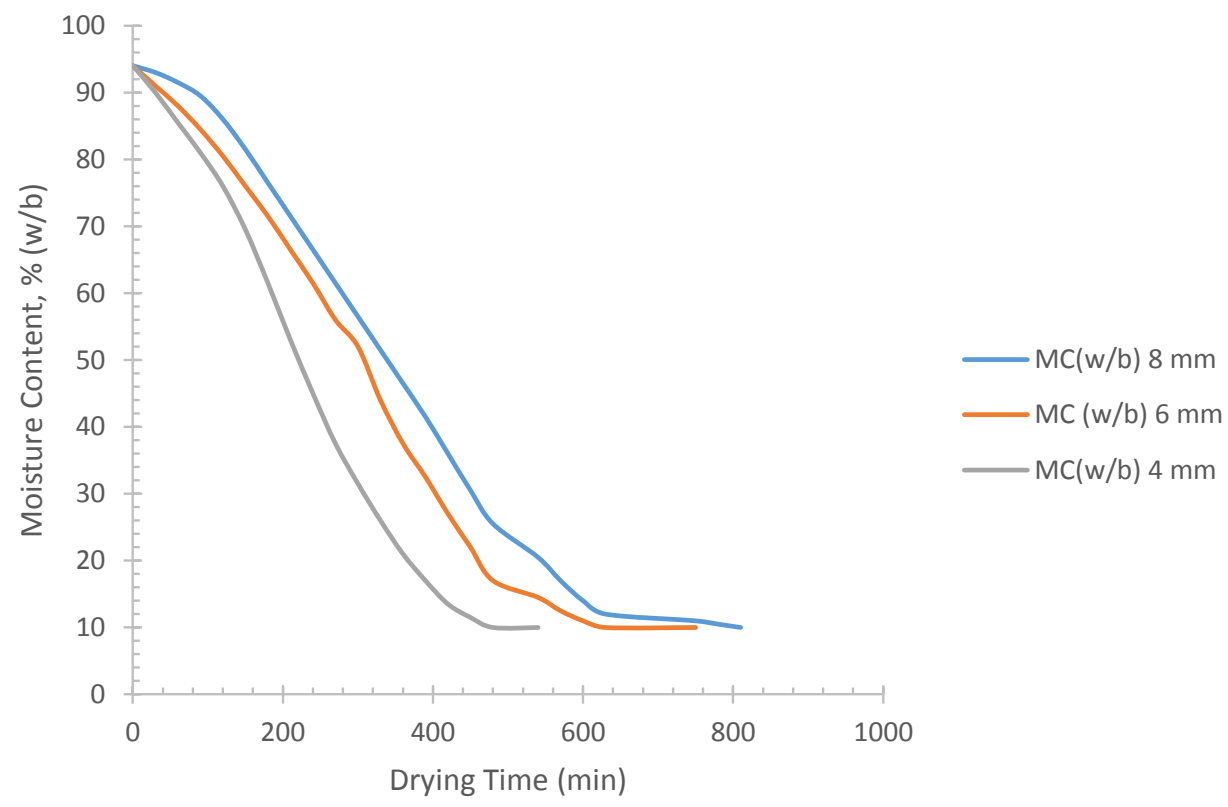

Figure 4: Drying Curve for Open Sun Drying Method.

that the time required to reduce the moisture content of tomato slices to any required moisture level depends on the drying conditions that are influenced by weather parameters. Similarly, Sacilik et al. (2006) also observed that the drying characteristics of tomato slices in solar tunnel and open sun drying methods were highly influenced by weather parameters.

\section{Mathematical Modelling of the Drying curves}

The summary of model parameters of the six thin layer drying models obtained from the non-linear regression of the models are shown in Tables 2, 3 and 4. It was observed that the Page model satisfactorily described the drying kinetics of tomato slices dried using hybrid, solar 
Table 2: Estimated Parameters and Comparison Criteria of Moisture Ratio for Hybrid Drying.

\begin{tabular}{|c|c|c|c|c|c|}
\hline Models & Models constants & Tomato thickness & $\mathbf{R}^{2}$ & $\mathrm{x}^{2}$ & RMSE \\
\hline \multirow{3}{*}{ Page } & $\mathrm{k}=0.286 \mathrm{n}=0.525$ & 4 & 1.000 & $4.44334 \times 10^{-6}$ & 0.00191 \\
\hline & $\mathrm{k}=0.161 \mathrm{n}=0.630$ & 6 & 1.000 & $1.59561 \times 10^{-5}$ & 0.00367 \\
\hline & $k=0.111 n=0.675$ & 8 & 1.000 & $1.45805 \times 10^{-5}$ & 0.00356 \\
\hline \multirow{3}{*}{ Logarithmic } & $k=0.057 \quad a=0.980 \quad b=0.019$ & 4 & 0.997 & 0.00033 & 0.01548 \\
\hline & $k=0.044 \quad a=0.979 \quad b=0.017$ & 6 & 0.997 & 0.00027 & 0.01446 \\
\hline & $k=0.034 \quad a=0.973 \quad b=0.019$ & 8 & 0.995 & 0.00039 & 0.01769 \\
\hline \multirow{3}{*}{ Henderson and Pabis } & $k=0.053 \quad a=0.997$ & 4 & 0.994 & 0.00060 & 0.02222 \\
\hline & $k=0.041 \quad a=0.995$ & 6 & 0.994 & 0.00050 & 0.02065 \\
\hline & $k=0.031 \quad a=0.988$ & 8 & 0.991 & 0.00064 & 0.02347 \\
\hline \multirow{3}{*}{ Newton (Lewis) } & $k=0.053$ & 4 & 0.994 & 0.00054 & 0.02223 \\
\hline & $\mathrm{k}=0.041$ & 6 & 0.994 & 0.00046 & 0.02070 \\
\hline & $k=0.032$ & 8 & 0.991 & 0.00060 & 0.02369 \\
\hline \multirow{3}{*}{ Wang and Singh } & $k=-0.012 \quad c=3.092 \times 10^{-5}$ & 4 & 0.471 & 0.05084 & 0.20396 \\
\hline & $k=-0.010 \quad c=2.171 \times 10^{-5}$ & 6 & 0.414 & 0.04781 & 0.20113 \\
\hline & $k=-0.009 \quad c=1.583 \times 10^{-5}$ & 8 & 0.417 & 0.04219 & 0.19123 \\
\hline \multirow{3}{*}{ Parabolic } & $\begin{array}{l}k=-0.008 \quad c=1.978 \times 10^{-5} \\
a=0.667\end{array}$ & 4 & 0.692 & 0.03333 & 0.15569 \\
\hline & $\begin{array}{l}\mathrm{k}=-0.006 \quad \mathrm{c}=1.321 \times 10^{-5} \\
\mathrm{a}=0.641\end{array}$ & 6 & 0.693 & 0.02758 & 0.14566 \\
\hline & $\begin{array}{l}k=-0.005 \quad c=9.431 \times 10^{-6} \\
a=0.636\end{array}$ & 8 & 0.720 & 0.02194 & 0.13247 \\
\hline
\end{tabular}

Table 3: Estimated Parameters and Comparison Criteria of Moisture Ratio for Solar Drying.

\begin{tabular}{|c|c|c|c|c|c|}
\hline Models & Models constant & Tomato thickness & $\mathbf{R}^{2}$ & $x^{2}$ & RMSE \\
\hline \multirow{2}{*}{ Page } & $\mathrm{k}=0.219 \mathrm{n}=0.554$ & 4 & 1.000 & $5.33838 \times 10^{-6}$ & 0.00354 \\
\hline & $\mathrm{k}=0.059 \mathrm{n}=0.710$ & 8 & 1.000 & $1.44509 \times 10^{-5}$ & 0.00220 \\
\hline \multirow{3}{*}{ Logarithmic } & $k=0.046 \quad a=0.977 \quad b=0.019$ & 4 & 0.996 & 0.00034 & 0.01636 \\
\hline & $\mathrm{k}=0.027 \quad \mathrm{a}=0.970 \quad \mathrm{~b}=0.018$ & 6 & 0.995 & 0.00032 & 0.01625 \\
\hline & $k=0.017 \quad a=0.943 \quad b=0.023$ & 8 & 0.989 & 0.00066 & 0.02376 \\
\hline \multirow[t]{2}{*}{ Henderson and Pabis } & $\mathrm{k}=0.025 \mathrm{a}=0.982$ & 6 & 0.991 & 0.00055 & 0.02215 \\
\hline & $k=0.016 \quad a=0.953$ & 8 & 0.984 & 0.00096 & 0.02943 \\
\hline \multirow{3}{*}{ Newton (Lewis) } & $k=0.043$ & 4 & 0.991 & 0.00059 & 0.02353 \\
\hline & $k=0.026$ & 6 & 0.991 & 0.00053 & 0.02255 \\
\hline & $\mathrm{k}=0.017$ & 8 & 0.992 & 0.00103 & 0.03131 \\
\hline \multirow{3}{*}{ Parabolic } & $\begin{array}{l}k=-0.005 \quad c=8.994 \times 10^{-6} \\
a=0.583\end{array}$ & 4 & 0.634 & 0.02774 & 0.14898 \\
\hline & $\begin{array}{l}k=-0.004 \quad c=6.152 \times 10^{-6} \\
a=0.614\end{array}$ & 6 & 0.722 & 0.01868 & 0.12478 \\
\hline & $\begin{array}{l}k=-0.003 \quad c=4.314 \times 10^{-6} \\
a=0.650\end{array}$ & 8 & 0.800 & 0.01251 & 0.10353 \\
\hline
\end{tabular}


Res. J. Food Sci. Nutr. 22

Table 4: Estimated Parameters and Comparison Criteria of Moisture Ratio for Open Sun Drying.

\begin{tabular}{|c|c|c|c|c|c|}
\hline Models & Models constant & Tomato thickness & $\mathbf{R}^{2}$ & $x^{2}$ & RMSE \\
\hline \multirow{3}{*}{ Page } & $\mathrm{k}=0.037 \mathrm{n}=0.791$ & 4 & 1.000 & $2.1903 \times 10^{-5}$ & 0.00441 \\
\hline & $\mathrm{k}=0.029 \mathrm{n}=0.801$ & 6 & 1.000 & $7.10241 \times 10^{-6}$ & 0.00254 \\
\hline & $k=0.003 n=1.178$ & 8 & 0.997 & 0.00021 & 0.01389 \\
\hline \multirow{3}{*}{ Logarithmic } & $k=0.015 \quad a=0.951 \quad b=0.019$ & 4 & 0.994 & 0.00047 & 0.01970 \\
\hline & $k=0.011 \quad a=0.943 \quad b=0.020$ & 6 & 0.994 & 0.00038 & 0.01822 \\
\hline & $\mathrm{k}=0.008 \mathrm{a}=1.049 \mathrm{~b}=0.000$ & 8 & 0.995 & 0.00047 & 0.02028 \\
\hline \multirow{3}{*}{ Henderson and Pabis } & $\mathrm{k}=0.014 \quad \mathrm{a}=0.960$ & 4 & 0.991 & 0.00062 & 0.02355 \\
\hline & $k=0.011 \quad a=0.950$ & 6 & 0.992 & 0.00055 & 0.02239 \\
\hline & $k=0.008 \quad a=1.049$ & 8 & 0.995 & 0.00045 & 0.02028 \\
\hline \multirow{3}{*}{ Newton (Lewis) } & $\mathrm{k}=0.015$ & 4 & 0.990 & 0.00070 & 0.02568 \\
\hline & $k=0.011$ & 6 & 0.989 & 0.00068 & 0.02551 \\
\hline & $k=0.008$ & 8 & 0.993 & 0.00059 & 0.02383 \\
\hline \multirow{3}{*}{ Wang and Singh } & $k=-0.006 \quad c=8.865 \times 10^{-6}$ & 4 & 0.695 & 0.02186 & 0.13940 \\
\hline & $k=-0.005 \quad c=4.926 \times 10^{-6}$ & 6 & 0.631 & 0.02437 & 0.14884 \\
\hline & $k=-0.004 \quad c=3.534 \times 10^{-6}$ & 8 & 0.837 & 0.01362 & 0.11195 \\
\hline \multirow{3}{*}{ Parabolic } & $\begin{array}{l}k=-0.004 \quad c=5.769 \times 10^{-6} \\
a=0.724\end{array}$ & 4 & 0.865 & 0.01031 & 0.09267 \\
\hline & $\begin{array}{l}k=-0.003 \quad c=3.038 \times 10^{-6} \\
a=0.697\end{array}$ & 6 & 0.857 & 0.00992 & 0.09257 \\
\hline & $\begin{array}{l}k=-0.003 \quad c=2.671 \times 10^{-6} \\
a=0.813\end{array}$ & 8 & 0.904 & 0.00845 & 0.08624 \\
\hline
\end{tabular}

and open sun drying methods followed by the Logarithmic model. Page model was also reported to give the best fit that describes the thin layer drying of some earlier studies. These include Akpinar et al. (2006) for aromatic plants; Doymaz, (2004) for carrots; and Hossain and Bala (2002) for green chillies; Kulanthaisami et al. (2010) for solar cabinet and open sun drying of tomato slices. Others are Bagheri et al. (2013) for solar dryer, shadow and open sun drying of tomato slices and Çelen et al. (2013) for vacuum drying kinetics of untreated tomato slices.

The experimental and the predicted data values using Page model for moisture ratios of tomato slices dried in hybrid, solar and open sun drying methods were shown in Figures 5, 6 and 7. The established model provided a very good conformity between the experimental data and the predicted moisture ratios of the tomato slices $(4,6$ and $8 \mathrm{~mm}$ ) dried under hybrid dryer, solar dryer and open sun drying methods. It was observed that the predicted data are banded around the ideal trend line indicating the suitability of the model in predicting the drying behaviour of tomato slices in hybrid dryer, solar dryer and by open sun drying. Queiroz et al. (2004) reported that drying curves could be well adjusted by the Page model and the model parameters were correlated as functions of drying conditions.

\section{Effective Moisture Diffusivity}

The mechanisms of mass transfer in food are complex in nature. The water migrates from the inside to the surface of the product under the effect of various mechanisms which can be combined. In this study, only a falling rate drying period, which resulted in shrinkage of the dried tomatoes was observed. Thus, the main mechanism of the water transport for the tomatoes slices is considered as diffusive type. The method of slopes as shown in Eq. (6) was used to calculate the effective moisture diffusivity coefficient. Slope of graphs of Ln (MR) versus time for the experimental drying were determined. The effective moisture diffusivity values were found to be $2.00-5.84 \mathrm{x}$ $10^{-10} \mathrm{~m}^{2} / \mathrm{s}$ in hybrid dried slices, $1.37-4.40 \times 10^{-10} \mathrm{~m}^{2} / \mathrm{s}$ in solar dried slices and $1.33-4.01 \times 10^{-10} \mathrm{~m}^{2} / \mathrm{s}$ in open sun dried tomato slices of 4 to $8 \mathrm{~mm}$ thicknesses.

The values of $D_{\text {eff }}$ obtained for open sun dried tomato slices was the least while that of hybrid dried tomato slices had the highest value which indicates that moisture diffusivity in tomato is affected by the drying temperature. Diffusivity is a function of material characteristics as well as drying temperature. Higher diffusivity values obtained in hybrid dried tomato slices might be due to relatively lesser shrinkage of slices when compared to solar and sun dried slices. It can be due to better circulation of air 


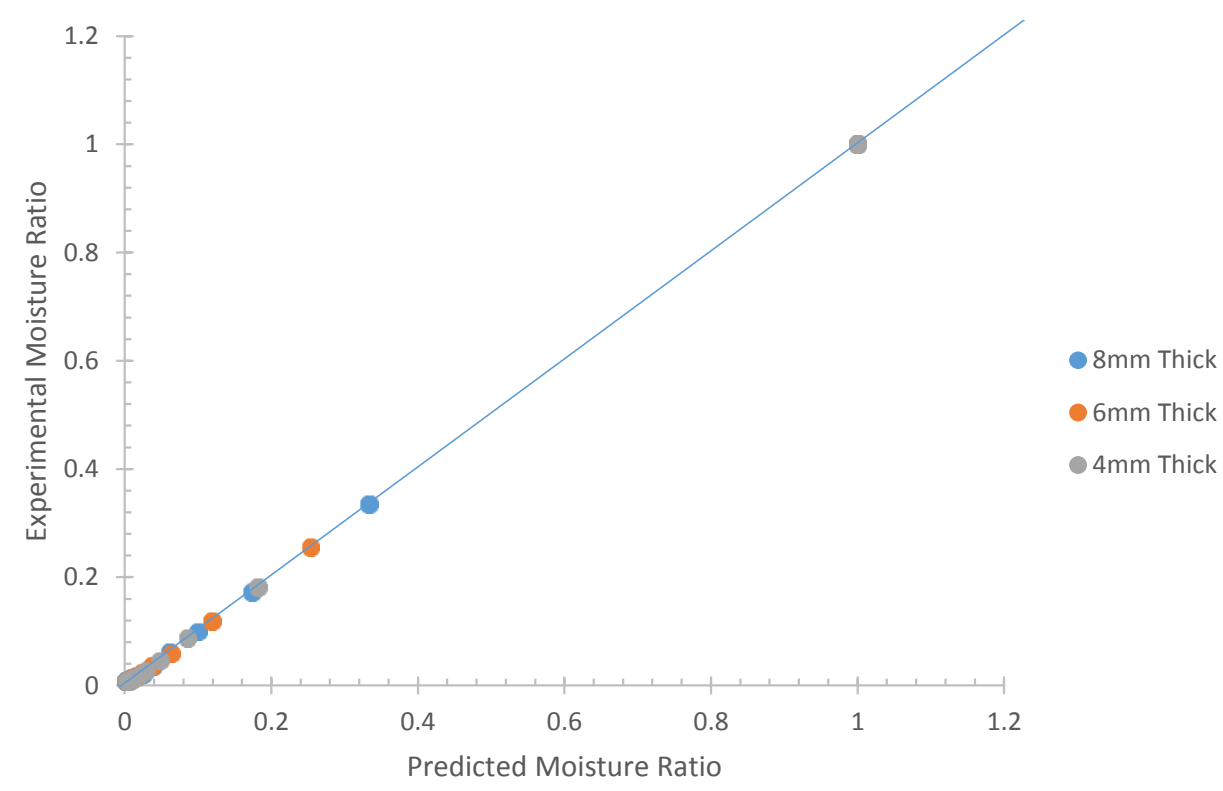

Figure 5: Experimental and Predicted Drying Curves for Tomato Slices under Hybrid Drying Method.

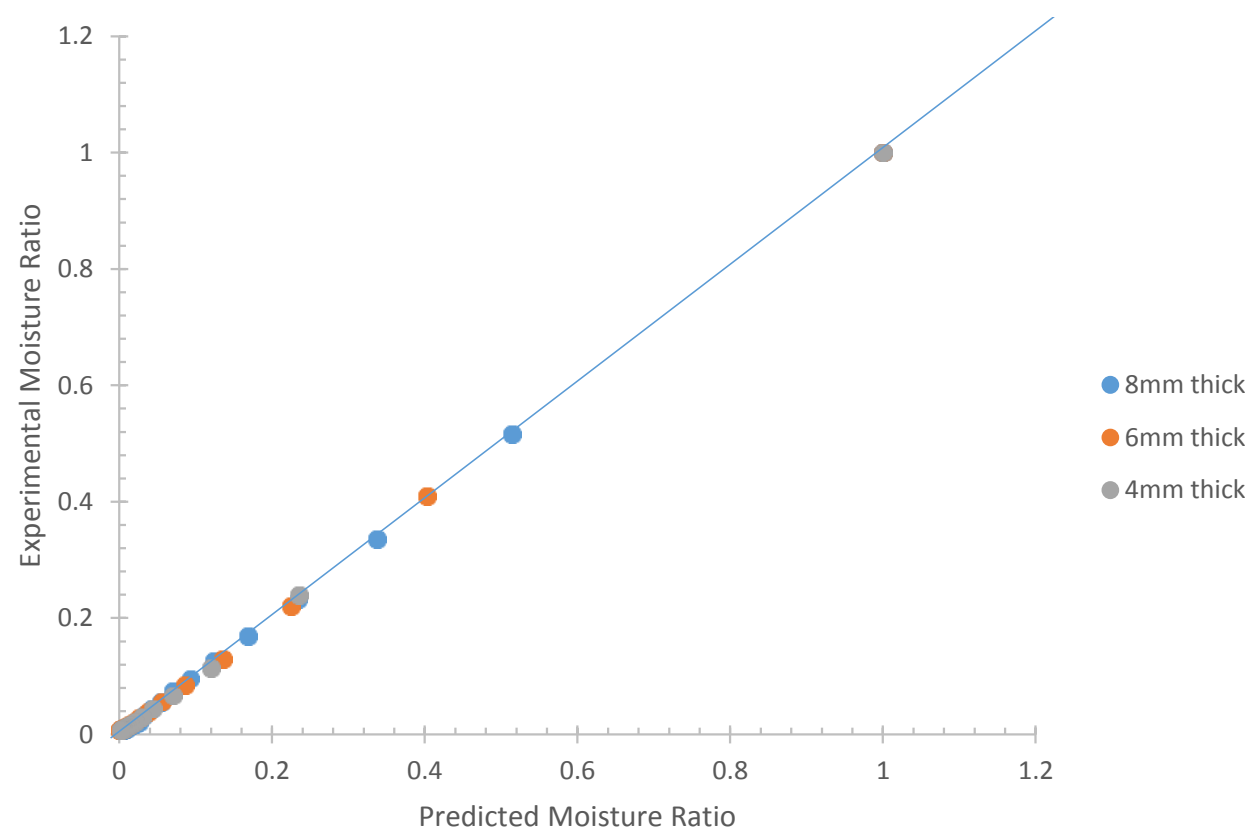

Figure 6: Experimental and Predicted Drying Curve for Tomato Slices under Solar Drying Method.

and perhaps also due to higher temperature and lower relative humidity (Rajkumar, 2007). The moisture from the inner core of the product migrates and replaces the surface and capillary moisture as they evaporated and eventually diffusion of moisture became the predominant mechanism. The drying temperature has a significant effect on the internal mass transfer during drying since the higher the drying temperature, the higher the rate at which diffusion of moisture from the internal regions to the surface occurs. This is because surface water 


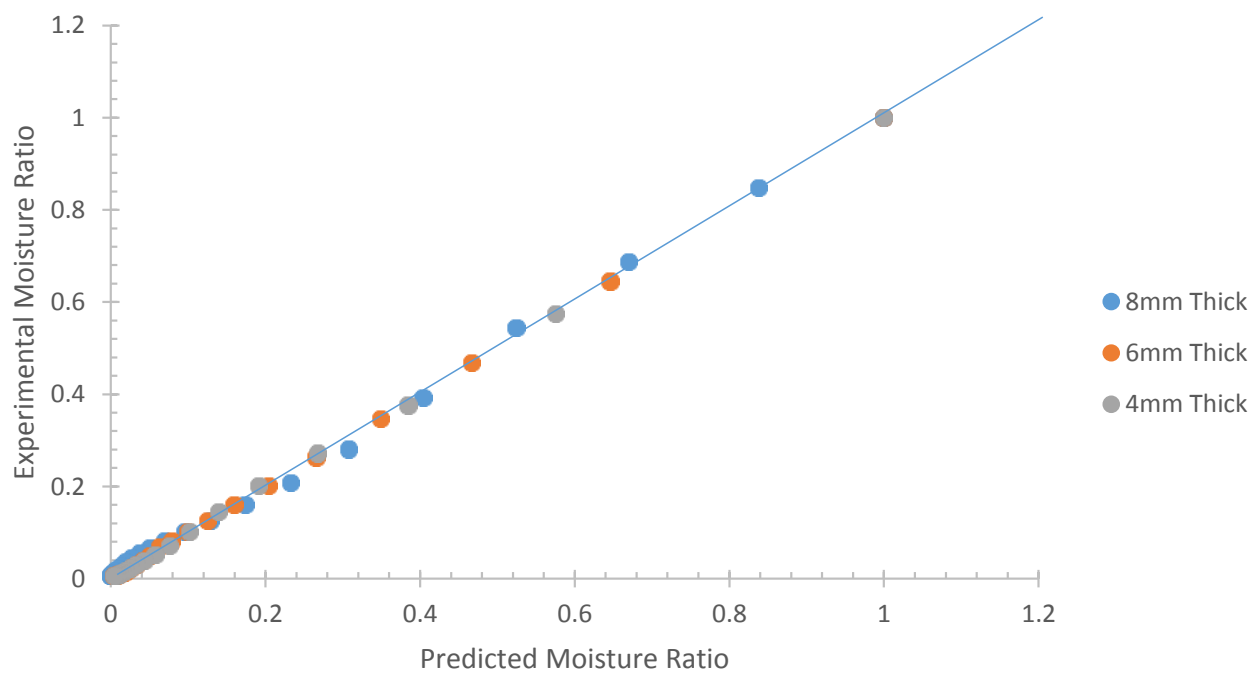

Figure 7: Experimental and Predicted Drying Curve for Tomato Slices under Open Sun Drying Method.

removal is faster at higher temperature since most of the drying mechanism is vapour diffusion. This is similar to that which was observed for date palm fruits and tiger nut seeds (Falade and Aboo, 2007; Tunde-Akintunde and Oke, 2012).

The Deff values obtained for tomatoes slices in this study lie within the general range of $10^{-12}$ to $10^{-8} \mathrm{~m}^{2} / \mathrm{s}$ for drying agricultural materials (Doymaz, 2010). They were also in comparison with the values reported by Sacilik et al. (2006) for open sun dried tomato slices $\left(1.31 \times 10^{-9}\right.$ $\mathrm{m}^{2} / \mathrm{s}$ ); Akanbi and Adeyemi, (2006) for tomatoes dried at $45^{\circ} \mathrm{C}$ to $75^{\circ} \mathrm{C}\left(3.72-12.27 \times 10^{-9} \mathrm{~m}^{2} / \mathrm{s}\right)$ and Doymaz (2007) for tomatoes dried at $55^{\circ} \mathrm{C}$ to $70^{\circ} \mathrm{C}(3.91-7.53 \mathrm{x}$ $10^{-10} \mathrm{~m}^{2} / \mathrm{s}$ ).

\section{Conclusions}

The study established that the time required to dry the tomato slices was comparatively lower in hybrid drying when compared to solar and open sun drying. The time required to dry $4 \mathrm{~mm}$ thickness tomato slice was lesser as compared to 6 and $8 \mathrm{~mm}$ thick slices. The drying rate and moisture diffusivity of tomato slices were higher in hybrid dryer. This study established that the drying behaviour of tomatoes slices occur in the falling rate period and Page model was found to be better in describing the drying kinetics. The study also concluded that the drying time and product temperatures were highly influenced by the weather parameters mainly temperature induced by solar insolation. The study has therefore provided information useful in drying process design for tomatoes which will assist in reducing losses often incurred during bumper harvesting and processing of tomatoes. It also proved that the efficiency of agricultural dryers could be increased through the use of a combination of solar and heating element coil powered by photovoltaic (PV) solar panel, compared to conventional dryers with only solar or only biomass heating sources.

\section{CONFLICT OF INTEREST}

The authors declare that they have no conflict of interest.

\section{REFERENCES}

Aghbashlo, M., Kianmehr, M. H., \& Arabhosseini, A. (2009). Modeling of Thin-Layer Drying of Potato Slices in Length of Continuous Band Dryer. Energy Conversion and Management, 50(5), 1348-1355.

Ajay, C., Orsunil, K. S., \& Deepak, D. P. (2009). Design of Solar Dryer with Turbo Ventilator and Fireplace. International Solar Food Processing Conference, Pp. 1-5.

Akanbi, C. T., \& Adeyemi, R. S. (2006). Drying Characteristics and Sorption Isotherm of Tomato Slices. Journal of Food Engineering, 73(2), 157-163.

Akpinar, E. K. (2010). Drying of Mint Leaves in a Solar Dryer and Under Open Sun: Modelling, Performance Analyses. Energy Conversion and Management, 51(12), 2407-2418.

Akpinar, E. K. (2006). Mathematical Modelling of Thin Layer Drying Process under Open Sun of Some Aromatic Plants. Journal of Food Engineering, 77(4), 864-870.

Akpinar, E. K., Bicer, Y., \& Yildiz, C. (2003). Thin Layer Drying of Red Pepper. Journal of Food Engineering, 59(1), 99-104.

Alibas, I. (2007). Energy Consumption and Colour Characteristics of Nettle Leaves during Microwave, Vacuum and Convective Drying. Biosys Engineering, 96(4), 495-502. 
Amer, B. M. A., Hossain, M. A., \& Gottschalk, K. (2010). Design and Performance Evaluation of a New Hybrid Solar Dryer for Banana, Energy Conversion and Management, 51: 813-820

Andritsos, N., Dalampakis, P., \& Kolios, N. (2003). Use of Geothermal Energy for Tomato Drying. GHC Bulletin, 9-13.

AOAC (2004). Official methods of Analysis, Association of Official Analytical Chemist, Washington D.C.

Arabhosseini, A., Huisman, W., van Boxtel, A., \& Müller, J. (2008). Modeling of Thin Layer Drying of Tarragon (Artemisia dracunculus L.). Industrial Crops and Products, 28(2), 53-59.

Aware, R., \& Thorat, B. N. (2012). Solar Drying of Fruits and Vegetables. In Solar Drying: Fundamentals, Applications and Innovations. (Hii, C.L., Ong, S.P., Jangam, S.V., \& Mujumdar, A.S. Eds.), ISBN - 978-981-07-3336-0, published in Singapore, pp. 51-72.

Babarinsa, F.A., Williams, J.O., \& Ngoddy, P.O. (2006). Development of a Hybrid Dryer with Kerosene and Solar Heat Source. Nigeria Drying Symposium Series, 2, 27-34.

Bagheri, H., Arabhosseini, A., Kianmehr, M. H., \& Chegini, G. R. (2013). Mathematical Modeling of Thin Layer Solar Drying of Tomato Slices. Agricultural Engineering International: CIGR Journal, 15(1), 146-153.

Bassey, M. W. (1985). Design and Performance of Hybrid Crop Dryer Using Solar-Energy and Sawdust. In: Proceedings of the ISES congress INTERSOL 85, Montreal, Canada, Oxford: Pergamon Press, 1038-1042.

Bennamoun, L., \& Belhamri, A. (2003). Design and Simulation of a Solar Dryer for Agricultural Products. Journal of Food Engineering, 59:259-66.

Berruti, F. M., Klaas, M., Briens, C., \& Berruti, F. (2009). Model for Convective Drying of Carrots for Pyrolysis. Journal of Food Engineering, 92(2), 196-201.

Boughali, S., Benmoussa, H., Bouchekima, B., Mennouche, D., \& Bouguettaia, H. (2009) Crop Drying by Indirect Active Hybrid-Solar-Electrical Dryer in the Eastern Algerian Septentrional Sahrta. Solar Energy, 83, 2223-2232.

Çelen, S., Kahvec, K., Akyol, U., \& Moralar, A. (2013). Drying Behaviour of Tomato Slices under Vacuum Conditions, TERMOTEHNICA Suplimet, 1, 58-65.

Crank, J. (1975). The Mathematics of Diffusion. Oxford University Press, London.

Da Silva, M. A., Pinedo, R. A., \& Kieckbusch, T. G. (2005). Ascorbic Acid Thermal Degradation during Hot Air Drying of Camu-Camu (Myrciaria dubia [H.B.K.] Mc Vaugh) Slices at Different Air Temperatures. Drying Technology, 23, 22772287.

Davies, J. N., \& Hobson, G. E. (1981). The Constituents of Tomato Fruit - The Influence of Environment, Nutrition, and Genotype. CRC critical Reviews in Food Science, and Nutrition, 15, 205-280.

Doymaz, I. (2004). Convective Air Drying Characteristics of Thin Layer Carrots. Journal of Food Engineering, 61, 359-364.

Doymaz, I. (2005). Drying Behaviour of Green Beans. Journal of Food Engineering, 69(2), 161-165.

Doymaz, I. (2010). Drying of thyme (Thymus Vulgaris L.) and Selection of a Suitable Thin-Layer Drying Model, Journal of Food Processing and Preservation, 35, 458 -465.

Doymaz, I. (2007). Air-Drying Characteristics of Tomatoes. Journal of Food Engineering, 78(4), 1291-1297.

Falade, K. O., \& Abbo, E. S. (2007). Air-Drying and Rehydration Characteristics of Date Palm (Phoenix dactylifera L.) Fruits. Journal of Food Engineering, 79, 724-730.

Funebo, T., \& Ohlsson, T. (1998). Microwave-Assisted Air
Dehydration of Apple and Mushroom, Journal of Food Engineering, 38, 353-367.

Geramitcioski, T., \& Mitrevski, V. (2011). Design and Construction of a New Mobile Solar Dryer, Second International Conference Sustainable Postharvest and Food Technologies INOPTEP 2011, Velika Plana. Pp. 24-26.

Gutti, B., Kiman, S., \& Ahmed, M. M. (2012). Solar Dryer - An Effective Tool for Agricultural Products Preservation. Journal of Applied Technology in Environmental Sanitation, 2(1), 3138.

Hassan-Beygi, S. R., Aghbashlo, M., Kianmehr, M. H., \& Massah, J. (2009). Drying Characteristics of Walnut (Juglans regia L.) During Convection Drying. Interl Agrophysics 23, 129-135

Hossain, M. A., \& Gottschaslk, K. (2006). Determination of Optimum Conditions for Half Fruits Drying Kinetics of Tomato. Bornimer Agric. Berichte, 55, 181-197.

Hossain, M. A., \& Bala, B. K. (2002). Thin Layer Drying Characteristics for Green Chilli. Drying Technology, 20(2), 489-505

Jangam, S. V., Joshi, V. S., Mujumdar, A. S., \& Thorat, B. N. (2008). Studies of Dehydration of Sapota (Achras zapota). Drying Technology, 26, 369-377.

Khazaei, J., Chegini, G. R., \& Bakhshiani, M. (2008). A Novel Alternative Method for Modeling the Effects of Air Temperature and Slice Thickness on Quality and Drying Kinetics of Tomato Slices: Superposition Technique. Drying Technology, 26, 759-775.

Kingsly, R. P., Goyal, R. K., Manikantan, M. R., \&llyas, S. M. (2007). Effects of Pretreatments and Drying Air Temperature on Drying Behaviour of Peach Slice. International Journal of Food Science and Technology, 42, 65-69.

Kulanthaisami, S., Rajkumar, P., Raghavan, G. S. V., Venkatachalam, P., Gariepy, Y., Subramanian, P., \& Orsat, V. (2010). Drying Kinetics of Tomato Slices in Solar Cabinet Dryer Compared with Open Sun Drying, Madras Agricultural Journal, 97 (7-9), 287-295

Midilli, A., \& Kucuk, H. (2003). Mathematical Modeling of Thin Layer Drying of Pistachio by using Solar Energy. Energy Conversion and Management, 44(7), 1111-1122.

Mirzaee, E., Rafiee, S., \& Keyhani, A. (2010). Evaluation and Selection of Thin-Layer Models for Drying Kinetics of Apricot (cv. NASIRY). Agric. Eng. Int: CIGR Journal, 12(2), 111-116.

Mohamed, A., M. Kouhila, A. Jamali, S. Lahsasni, N. Kechaou, \& M. Mahrouz, (2005). Single Layer Solar Drying Behaviour of Citrus aurantium Leaves under Forced Convection. Energy Conversion and Management, 46(9-10), 1473-1483.

Owusu, J., Haile, M., Zhenbin, W., \& Agnes, A. (2012). Effect of Drying Methods on Physicochemical Properties of Pre-treated Tomato (Lycopersicon esculentum mill.) Slices. Croatian Journal of Food Technology, Biotechnology and Nutrition 7 (1-2), $106-111$

Prasad, J., \& Vijay, V. K. (2005). Experimental Studies on Drying of Zingiber officinale, Curcuma longa L. and Tinospora cordifolia in Solar-Biomass Hybrid Dryer. Renew Energy, 30, 097-109.

Puiggali, J. R., \& Varichon, B. (1982). First Prototypes for Small Fruit and Vegetable Country Solar Dryers. In: Mujumadar AS, editor. Drying '82. Washington: Hemisphere Pub. Corp., Pp. 208-213.

Purkayastha, M. D., Nath, A., Deka, B. C., \& Mahanta, C. L. (2013). Erratum to: Thin Layer Drying of Tomato Slices. Journal of Food Science and Technology, 50, 654-654. 
Queiroz, R., Gabas, A. L., Telis, \& V. R. N. (2004). Drying Kinetics of Tomato by using Electric Resistance and Heat Pump Dryers. Drying Technology, 22(7), 1603-1620.

Rajkumar, P. (2007). Comparative Performance of Solar Cabinet, Vacuum Assisted Solar and Open Sun Drying Methods. A Thesis submitted to the Department of Bioresource Engineering, McGill University Montreal, Canada. In partial fulfilment of the requirements for the Degree of Master of Science.

Reyes, A., Mahn, A., Huenulaf, P. \& González, T. (2014) Tomato Dehydration in a Hybrid-Solar Dryer. Journal Chemical Engineering Process Technology 5 (4), 1-8.

Sacilik, K., Keskin, R., \& Elicin, A.K. (2006). Mathematical Modeling of Solar Tunnel Drying of Thin Layer Organic Tomato, Journal of Food Engineering 73(3), 231 - 238.

Sharma, G. P., \& Prasad, S. (2004). Effective Moisture Diffusivity of Garlic Cloves undergoing Microwave-Convective Drying. Journal of Food Engineering, 65, 609-617.

Shittu, T. A., \& Raji, A. O. (2011). Thin Layer Drying of African Breadfruit (Treculia africana) Seeds: Modelling and Rehydration Capacity, Food Bioprocess. Technol., 4, 224231.

Singh, S., Raina, C. S., Bawa, A. S., \& Saxena, D. C. (2006). Effect of Pretreatments on Drying and Rehydration Kinetics and Colour of Sweet Potato Slices. Drying Technology 24, 1487-1494.

Singhanat, P., \& Anong, S. (2010). Spray-Drying of Ginger Juice and Physicochemical Properties of Ginger Powders Science Asia, 36, 40-45

Togrul, I. T., \& Pehlivan, D. (2002). Mathematical Modeling of Solar Drying of Apricots in Thin Layers. Journal of Food Engineering, 55, 209-216
Tunde-akintunde, T. Y., \& Oke, M. O. (2012). Thin-Layer Drying Characteristics of Tiger Nut (Cyperus esculentus) Seeds. Journal of Food Processing and Preservation. 36, 457-464.

Tunde-Akintunde, T. Y. (2011). Mathematical Modeling of Sun and Solar Drying of Chilli Pepper. Renewable Energy, 36(8), 2139-2145.

Tutuncu, M. A., \& Labuza, T. P. (1996). Effect of Geometry on the Effective Moisture Transfer Diffusion Coefficient. Journal of Food Engineering, 30(3-4), 433-447.

Vlachos, N. A., Karapantsios, T. D., Balouktsis, A. I., \& Chassapis, D. (2002). Design and Testing of a New Solar Tray Dryer. Drying Technology; 20(6), 1243-71.

Wang, C. Y. and Singh, R. P. (1978). A Single Layer Drying Equation for Rough Rice. ASAE paper no. 3001.

Werner, W., \& Josef, B. (2003). Solar Drying. Training Courses with the Scope of the Project: Establishment of a Production, Sales and Constructing Infrastructures for Solar Thermal Plants in Zimbabwe.

Xanthopoulos, G., Lambrinos, G., \& Manolopoulou, H. (2007). Evaluation of Thin-Layer Models for Mushroom (Agaricus bisporus) Drying. Drying Technology 25, 1471-1481.

Zhang, M., Tang, J., Mujumdar, A. S., \& Wang, S. (2006). Trends in Microwave Related Drying of Fruits and Vegetables, Trends in Food Science and Technology, 17, 524-534. 


\section{NOMENCLATURE}

$\begin{array}{lll}a, b, c, n & \text { the drying coefficients in thin-layer equations } & \mathrm{s}^{-1} \\ D_{\text {eff }} & \text { effective moisture diffusivity } & \mathrm{m}^{2} / \mathrm{s} \\ k & \text { drying rate constant } & \mathrm{s}^{-1} \\ \mathrm{~L} & \text { half thickness of a thin layer sample } & \mathrm{m} \\ \mathrm{Me} & \text { equilibrium dry basis moisture contents } & \mathrm{kg} / \mathrm{kg} \text { dry tomato slice } \\ \mathrm{Mi} & \text { initial dry basis moisture contents } & \mathrm{kg} / \mathrm{kg} \text { dry tomato slice } \\ \mathrm{MR} & \text { moisture ratio } & \mathrm{kg} / \mathrm{kg} \text { dry tomato slice } \\ \mathrm{Mt} & \text { dry basis moisture content at any time ' } \mathrm{t} \text { ' } & \\ \mathrm{N} & \text { drying power factor in thin-layer equations } & \\ \mathrm{R}^{2} & \text { coefficient of determination } & \mathrm{s} \\ \mathrm{RMSE} & \text { root mean square error analysis } & \\ \mathrm{t} & \text { drying time } & \\ \mathrm{X}^{2} & \text { reduced chi-square } & \end{array}$

